\title{
In-Situ Mechanical Property Evaluation of Dielectric Ceramics in Multilayer Capacitors
}

\author{
A. A. Wereszczak, L. Riester, and K. Breder' \\ Mechanical Characterization and Analysis Group, Oak Ridge National Laboratory, Oak Ridge, TN 37831-6069
}

Copyright 1998 Society of Auromotwe Englneert, the.

\begin{abstract}
The Young's modulus, hardness, and fracture toughness of barium titanate dielectric coramics in three commercially avaikable multilayer capacitors (MLCs) were measured in-situ using indentation and a mechanfical properties microprobe. The three MLCs were equivalent in size (0805), capacitance $(0.1 \mu \mathrm{F})$ and dielectric type (X7R). The Young's modulus and hardness of the dielectrtic ceramics in the three MLCs were sirrilar, whitle there were statlstically significant differences in their tracture toughnesses. The provids provide insight into the assessment of MLC mechanical refiability, and show that equivalent electrical MLC rating is not necessarily a guarantee that the dielectric cerarnics in them wil exhibit equivalent mechanical performance.
\end{abstract}

\section{INTRODUCTION}

Ceramic multilayer capacitors are compticated structures consisting of several different materials. If the mechanical reliabllty of the ceramic constituants in the MLC imits its electric service function or reliabitity or its manulacturability, then there is merit in understanding and predicting their mechanical performance. Understanding the mechanical reliability of cerarric MLCs is complex. however, because many parameters can aftect it. All these paramelers may be grouped into two categories: material parameters that describe the dielectric ceramic's mechanical properties and design parameters that can dictate what (thermo)mechanical stresses are imposed on the MLC during its service or manufacture [1-2]. The present study focused on parameters in the former category.

The mechanical performance of diefectric ceramics in MLCs is long recognized as being importart to dependable service life; however thelr evaluation has become experimentally more complicated over the last several years. Freiman and Pohanka [3] published an exceilent review approximately 10 years ago on the mechanical properties of barium titanate $\left(\mathrm{BaTlO}_{3}\right)$ ceramics.

The furtter-minfaturization of MLCs since Frelman and Pohanka's revlew has resulted in (1) new MLCs and dielectric ceramics that are much different from those investigated and (2) test techniques that need refinement for testing them. The grain sizes of $\mathrm{BaTiO}_{3}$ dielectric ceramics have been greatly reduced, and that has allowed the dielectric layer thicknesses to be made significantly smaller as a consequence. This in tum has greatly increased the capacitance/volume ratio of contemporary MLCs. Due to the lessening size of dielectric cerarnic layers, margins, and cover layers in contemporary MLCs, standard mechanical properties tests such as flexure strength, mlcrohardness, and fracture toughness by indentation cannot be readily performed. Consequently, valid mechanical property meesurement must be conducted on a much smaller scale.

Depending on their capacitance and operating voltage, MLCs can have a wide variety of physical sizes as shown in Figs. 1-2. The MLCs examined in the present study are the smaller of the two sizes shown in Fig. 1 , and have an operation rating of $10 \mathrm{~V}$. The procedures and analyses are easily extendable to the larger-sized MLCs. shown in Fig. 2, which are candidates for automotive power eiectronics and operate at 500-600 V.

\section{PROCEDURES}

The BaTiO, dielectric ceramics in equivalent MLCs (X7F, $0805,0.1$ (F) manufactured by three different suppliers were mechankally characterized. Each MLC's manufacturer wes kept anonymous, and designated in the present study as MLC-A, MLC-B, and MLC-C.

\footnotetext{
${ }^{1}$ Now with Higgins Grinding Technology Center, Saint-Gobain Abrasives, Worcester, MA.
} 
Figure 1. Examples of 0805 and 1206 multilayer capacitors. The dielectric œeramics in $08050.1 \mu \mathrm{F} \times 7 \mathrm{R}$ capacitore were examined in the present study.

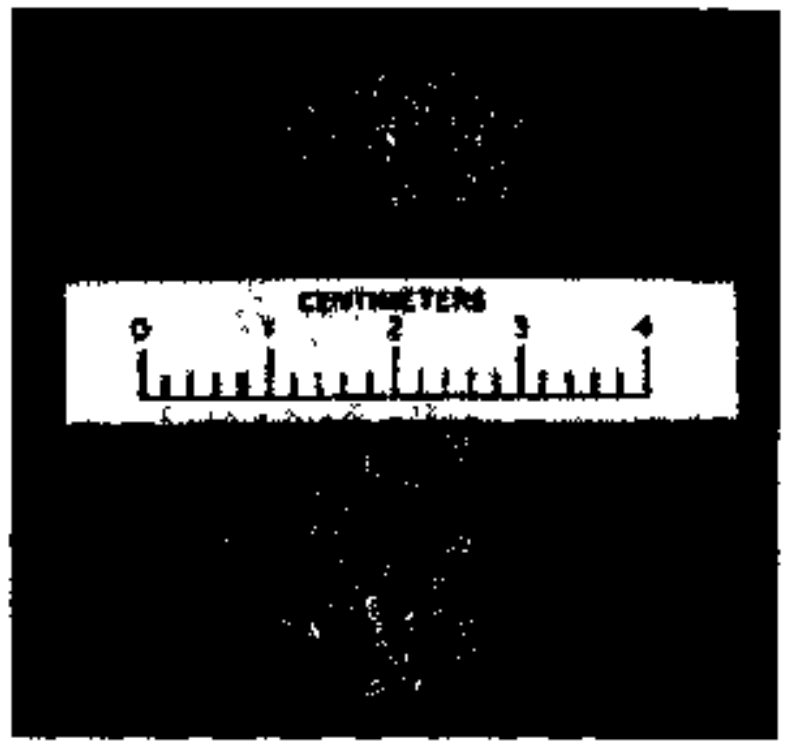

Figure 2. Examples of high-voltage, high-capacitance ceramic muttlayer capacitors that are amenable for use in atutomothe power electronics.

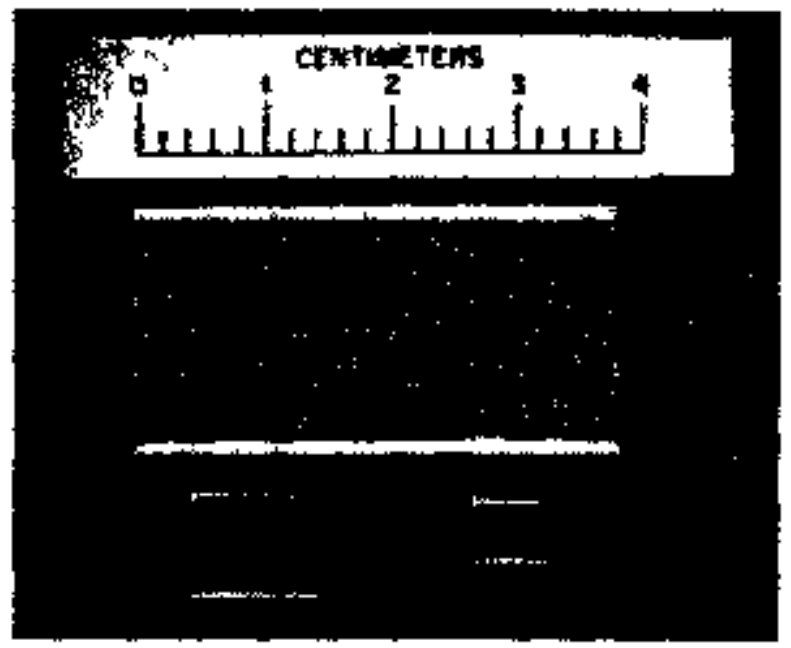

\section{MLC SAMPLE PREPARATION}

The MLCs exarrined possessed an orthotropic symmetry, so several firom each of the three manufacturers) were sectioned in half along each of the three orthogonal planes to completely reveal their internal electrode/dilelectric georretry (shown in Flg. 3). A fine surtace finish was prerequisite for the planned micromechanical testing. To achiewe this, the MLCs were sectioned, then set In metallographer's mouning epoxy and dlamond-paste polished to a $0.25 \mathrm{\mu m}$ finish.

\section{IN-SITU MECHANKCAL PROPERTY TESTING}

A mecthanucal properties microprobe (MPM) ${ }^{2}$ was used in the measurgment of the Young's modulus (E), hardness $(H)$, and for the determination of fracture toughness $\left(K_{\text {ret }}\right)$ of the delectric cerarnic in each of the three MLCs. The MPM is an automated instrument that consists of four pnmary components shown in Fig. 4.: an indenter whose vertical displacement (nanometer resolution) and applied load (merogram resolution) an controllable, an optical microscope (OM) with several objective lenses, a precision $X \& Y$ stage that iransiales the metallographically prepared specimen between the OM and the indenter, and a computer that controls the OM's fens turret (50-1500x magnification), stage movement. and indenter load and displacement. A diamond Berkowich indenter was used for the $E$ and $H$ measurements, while a diamond Vickers indenter was used for the $K_{k}$ measurements. The computer also collects data on the indenter's displacement and hoad. and is also interfaced with a TV-rnonitor and carnera that show the microscope's field of view and allow inspection of each indent.

The MPM (not including the computer) is housed Inside an Insulated cabinet that minimizes its susceptibility to laboratory rom temperature fluctuations and vibrations (problematic when controlling displacements at the nanometer level). The computer is outside the insulated cabinet to furlher minimize the introduction of thermal instabulitios, and remotely operates the MPM.

Figure 3. The multilayer capacitors were orthogonally sectoned to reveal their intemal layout.
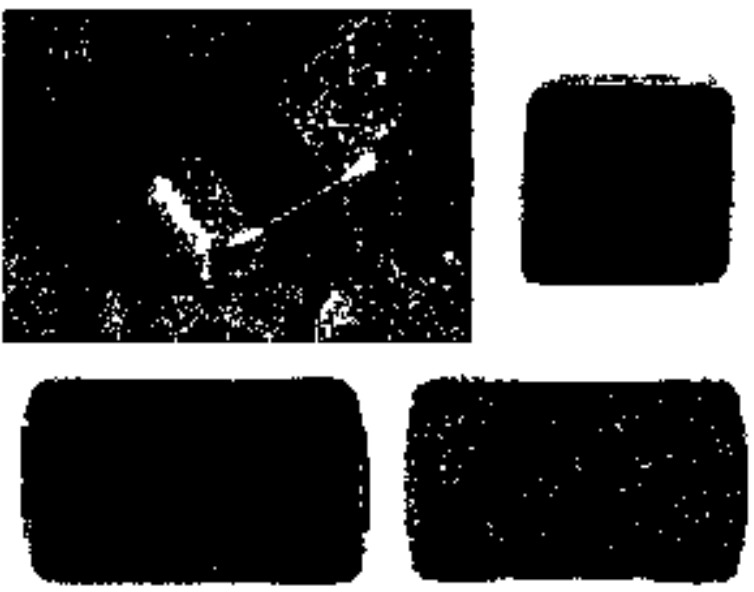

2 Nanoindenter II, Nano Irstruments, Dak Ridge, TN 
Figure 4. A mechanical properties microprobe was used for the testing.

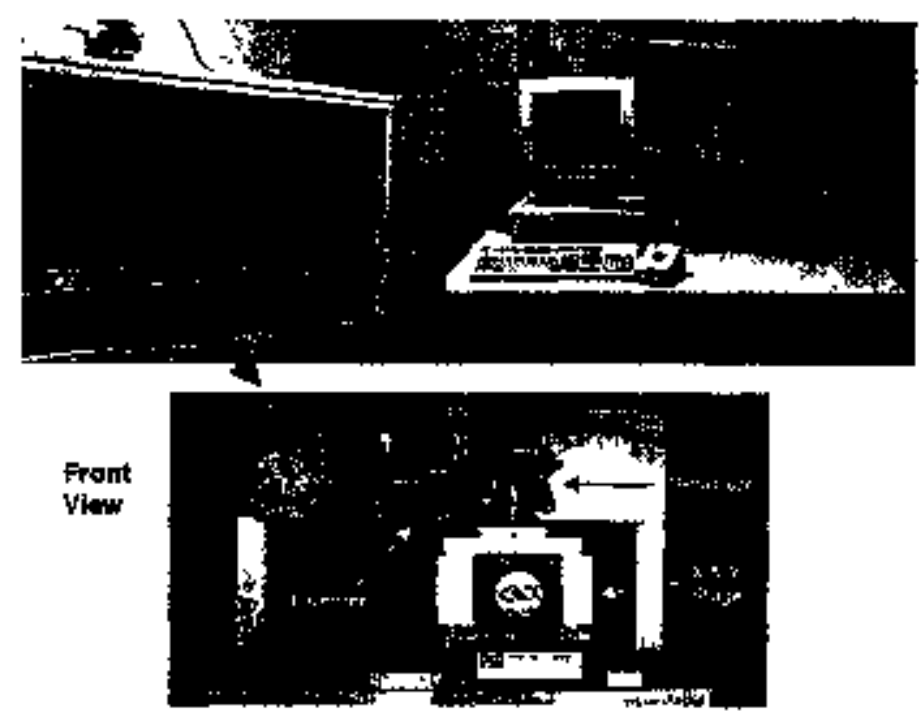

A load-displacement curve is obtained for each Indent. The relative contribution of elastic and plastic deformatlon can be assessed from this curve, and values for $\mathrm{H}$ and $\mathrm{E}$ determined.

For the present testing, a cover layer in each MuC was chosen to be subjected to indentation. Crack growth during fracture toughness testing can be affected by residual strasses; consequently. the cover layer region was chosen to be at a location (i.e., as far away from the termination metal as allowed) where their effects were at a minimum.

Addrionally, the plastic deformation zone created in the volume of matangl irtumediately under the indent has a tinite size. The cover layer region had a relattuely large volume and each indent's plastic zone in this region was not restricted by ediges; this provided another motivation to apply indents in this location. The dielectric layers between electrodes were quite thin, so indentation was not performed in that region owing to concerns that edge effects would result in misteading values of $E, H$, and $K_{\text {te }}$.

\section{Yosing's Moddenlus and Hardness}

Relatively low bads applied with the Berkovich indenter were used for the $E$ and $H$ determinations (no cracks produced), while higher loads were used for the $K_{k}$ determinatıons (cracks purposely produced). The load/displacement history during indentation provided data whlch were interpreted with the aid of an appropriate modet to calcuiate $E$ and $H$ of the material [4]. Forty indents were applled in the dielectrlc coramic in each MLC's cover layer, and the corresponding average $E$ and $H$ were calculated for each of them. A typical indent aray Is shown in Fig. 5.

\section{Fracture Toughness}

Higher loeds were applled with the Vickers indenter to produce cracks which emanated from the comers of the indent, and these cracks were used to determine $\mathrm{K}_{\mathrm{le}}$ The polished mesallographical molmts were carboncoated to improve conductwity of the sample. The indent-generated cracks wera lmaged at magnifications of 7000 and $10000 x$ with a scanning electron microscope (SEM) to measure their lengths. An image of an indent and its generated cracks are shown in Fig 6 . The crack length, its corresponding applied indent load. and the measured $E$ and $H$ lor each MC dielectric ceramic were needed to calculate $K_{k}$ using [5]

$$
\mathbf{K}_{\mathrm{k}}=\zeta\left[\frac{\mathrm{E}}{\mathrm{H}}\right]^{\frac{1}{2}}\left[\frac{\mathbf{P}}{c^{\frac{3}{2}}}\right] \text {. }
$$

where $\zeta$ is a material independent constent for the Vickers indenter, $E$ is the elastlc modulus, $H$ is the hardness, $P$ is the applied load, and $c$ is crack length (see Fig. 6). Analyses perfomed by the authors showed that the use of Eq. 1 is valid for use with the small indents produced by the MPM I6]. The values of $E$ and $H$ used in Eq. 1 were those measured with the MPM-generaled crack-free indents. Twenty indents were applied at high loads to produce cracks, and up to four cracks were produced per indent. However, many indents ottd not have tour cracks, so the number of tracture toughness values comprising the average was less than eighty for all three sets.

The anatysis of these properties using a Vickers indenter wilh a conventional microhardness tester is standard; however, such indents would be much larger than the sizes of the cover layers, margins, and end margins in these MLCs. The indents generated with a MPM on the other hand are much smaller than those generated with a standard hardness lester (a few microns versus hursdreds of microns): therefore, the MPM is a more suitable probe for dielectrlc ceramic mechanjcal testing. The imvestigators of this siudy are not aware (i.e., no literature relerences found) of the MPM being used by others to mechanically charactenze the various dielectric constituents in a MLC so the described test technique in combination with the analyses in this report may be the first of its kind. 
Figure 5. Indents were applied to the cover layer region within the muttlayer capactors.

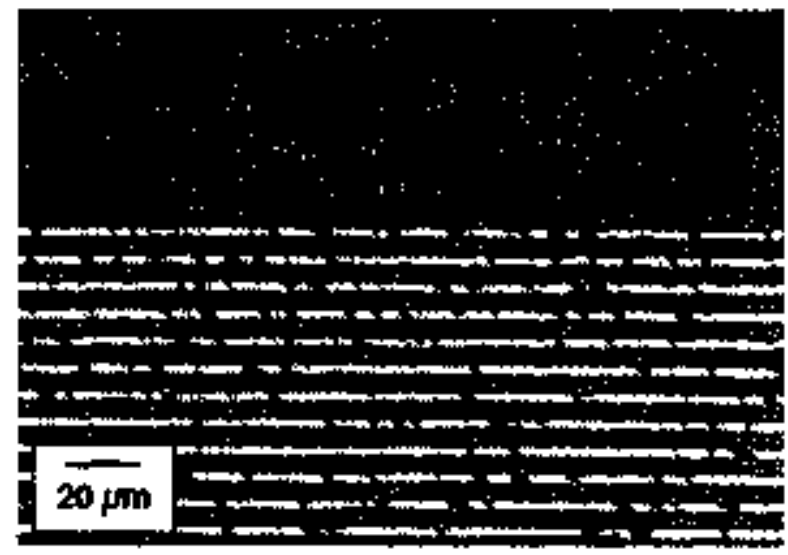

Figure 6. An enlargement of the boxed-reglon in Fig. 5 . The lengths of cracks produced by the high-load indents were measured and used in the fracture toughness calculation.

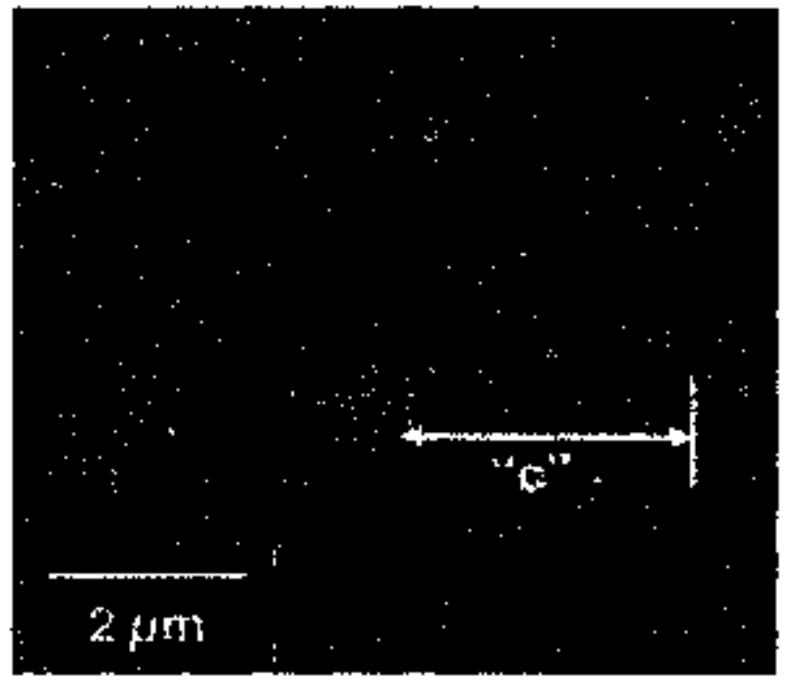

\section{RESULTS AND DISCUSSION}

\section{YOUNG'S MODULUS AND HARDNESS}

The Young's modulus of the dielectric ceramic in the MLC-C was stightly higher (203 GPa) than that for the dielectric ceramics in the MLC-A (199 GPa) and MLC-B (192 MPa). The dfference between the former and the latter two E's is statistically significant though small. The hardnesses of the dielectric ceramics in each of the three MLC systems were statistically equivalent. The average $E$ and $\mathrm{H}$ for the dielectrics in the three Investigated MLCs are listed in Table 1, along with this standard deviatlons.
Table 1. Measured mechanical properties of dielectric ceramics.

\begin{tabular}{|c|c|c|c|}
\hline Property & MLC-A & MLC-B & MLC-C \\
\hline $\begin{array}{c}\text { Yotung's } \\
\text { Modulus, } \\
\text { E, } \\
\text { (GPa) } \\
\text {-Average. }\end{array}$ & $\begin{array}{r}193 \\
40 \text { tests } \\
\end{array}$ & $\begin{array}{r}192 \\
40 \text { tesis } \\
\end{array}$ & $\begin{array}{c}203 \\
40 \text { to하노 } \\
\end{array}$ \\
\hline $\begin{array}{c}\text { Young's } \\
\text { Modulus, } \\
E_{1} \\
\text { (GPa) } \\
\text { Stan. Dev. }\end{array}$ & 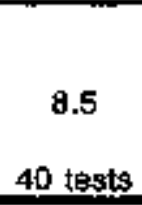 & $\begin{array}{c}9.2 \\
\text { 40) tessts } \\
\end{array}$ & $\begin{array}{c}7.7 \\
40 \text { tosis }\end{array}$ \\
\hline $\begin{array}{c}\text { Hardiness, } \\
H_{2} \\
\text { (GPe) } \\
\text { Average: }\end{array}$ & $\begin{array}{c}11,3 \\
40 \text { tesis }\end{array}$ & $\begin{array}{r}11.3 \\
40 \text { tests }\end{array}$ & $\begin{array}{c}11,9 \\
40 \text { tests }\end{array}$ \\
\hline $\begin{array}{c}\text { Hardness, } \\
\text { H, } \\
\text { (GPa) } \\
\text {-Stan. Dew. }\end{array}$ & $\begin{array}{c}1.0 \\
40 \text { tests }\end{array}$ & $\begin{array}{c}0.9 \\
40 \text { tgsts }\end{array}$ & $\begin{array}{c}0.6 \\
40 \text { tests } \\
\end{array}$ \\
\hline $\begin{array}{c}\text { Fracture } \\
\text { Toughness } \\
\text { K}_{n} \\
\text { (MPavim) } \\
\text {-Average- }\end{array}$ & $\begin{array}{c}1.36 \\
49 \text { tests } \\
\end{array}$ & $\begin{array}{r}1.11 \\
65 \text { tasts } \\
\end{array}$ & $\begin{array}{r}1.53 \\
65 \text { tests } \\
\end{array}$ \\
\hline $\begin{array}{c}\text { Fracture } \\
\text { Toughness } \\
K_{k} \\
\text { (MPav' } \\
\text { (Stan, Dev.- }\end{array}$ & $\begin{array}{c}0.29 \\
49 \text { tests }\end{array}$ & $\begin{array}{c}0.28 \\
65 \text { tests }\end{array}$ & $\begin{array}{c}0.47 \\
65 \text { tests }\end{array}$ \\
\hline
\end{tabular}

The Young's moduli of the dielectrk ceramic and termination metal in each of the three MLCs are not direct indicators of the potential machanical integrity of the MLCs. However, thejr values can provide some insights. Principally, it the dielectric ceramic in a MLC has a rejatively large-valued Young's modulus, then the imposed stresses in it will be higher than it its $E$ were lower-valued (for the same applied strain). The $E$ of the dielectric in the MLC.C is approximately $5 \%$ larger than the $E$ of the dielectrics in the MLC-A and MLC-B, so stress in the MLC-C would be approximately $5 \%$ more if the three MLCs were subjected to the same amount of strain (e.g., all three mounted MLCs's flexed the same amourt on an epoxy board). The differences in stress due to the differences in the dielectric ceramic E's of the three MLCs are probably not significant and not an indicator of predicted mectantcal integrity among these three MLCs. The E's of the temination metal provlde some insight into their ductile nature; often a lowervalued $E$ for a metal is an inclicator that it cen deform more readily when subjected to stress. Furthermore, if a tenmination metal is more ductile, then it can more readily relieve stress concentrations. Utllizing termination mejals in the MLC with greater ductility is preferable because minimizing tensile stresses in MLCs will lessen the likelihood of mecharical fallure of the dielectric ceramics within them. 
The hardness of the diefectric ceramics is also not a direct indicator of the potential MLC mechanicali robustness, but hs value can also provide some Insight into the effects of porosity and grain size on it. Hardiness is typically imverse to the amount of porosity. This is often observed and explolted with conventional microhardness testing where the indent samples a very lerge number of pores and is hundreds of microns in slze. However, with indents in the present study only being a few microns in stze (see Flg. 6), and only perhaps an order of magnitude larger in size than the pores, the relationship between hardness and porosity at the operating-size-scale of the MPM cannot be readily interpreted. Lastly, the measured hardnesses were more representative of the hardness of the $\mathrm{BaTiO}_{3}$ grains because the MPM produced an indent size that sampled regions consisting of sub-micron grains; conversely. this is not always the caso for microhardness testing because the large indent size it produces samples many more gtains, but also porosity, grain boundaries, etc.

Qualitatively, if the average pore size is small, then the fracture toughness of the cerarnic may be relatively high because crack growth may be inhibited or arrested by the pores. Conversely, the average pore size is relatively large, then the pores may act as actual strength-limiting flaws with the effect of towering the strangth of the ceramic. The hardness of the dielectric ceramics in the three examined MLCs were in fact equivalent, so if these were active effects, then they were equivalent in the three different dielectric ceramios.

\section{FRACTUFE TOUGHNESS}

The $\mathrm{K}_{1 \mathrm{t}}$ of the MLC-C (1.53 MPavim) was larger than that for the MLC-A (1.36 MPavm) which in tum was larger than that for MLC-B (1.11 MPaVm). The fracture toughness of another $\mathrm{BaTh}_{3}$ (as measured with microhardness indentation testing) was measured to range from 1 to $1.8 \mathrm{MPa} / \mathrm{m}$ [7-8]. Fracture toughness in $\mathrm{BaTiO}_{3}$ can depend on several varables including grain size, chemical composition, and crystad structure [3]. The differences among the average fracture toughnesses were slatistically significant and conclusive. The average $K_{*}$ values for the dielectric ceramics in these three MLC sysiems are listed in Table 1 and illustrated in Fig. 7 . Lastly, brittleness and hardness have been shown to be intertelated [9] in that hard materials are more apt to be byttle (i.e., have lower fracture toughness); however, the statistkally signticant difference in frecture toughnesses in these matertals did not manifest itself in different hardnesses, so this relattonship is not evident in these barium titanate ceramics.

Ceramics with maximum $K_{\text {w }}$ are preferable for load. bearing applications. Dielectric ceramics in MLCs may be subjected to tensile stresses during manulacturing or service, so using a dielectric ceramic with maxmum $\mathrm{K}_{\mathrm{Ic}}$ with minimize the likelihood of mechanical falure. A design window is schematically shown in Fig. 8 and it itustrates that a larger-valued fracture toughness increases the design wirdow or the device survivability. The dielectric ceramic in the MLC-C had the highest $K_{\text {lac }}$. while the dlelectrlc ceramic in the MLC-A had the secono highest $K_{k}$ and that in the MLC-B had the lowest. All other things belng equal, the dlelectric ceramic in the MLC-C would have the best mechanical integrity and would have the lowest likelihood of mechanical failure of the thres MiCs If they were subjected to equivalent mechanical loadings.

\section{CLOSING COMMENTS}

Other factors, although not quantified in this study. can also affect mechanical performance and should be considered in the optimization of MLC mechanical robustness. Paramaters such as electrode centering, cover layer and margin thicknesses, deformation

Figure 7. Fracture toughness comparison of the dielectric ceramic toughness in the three MLCs.

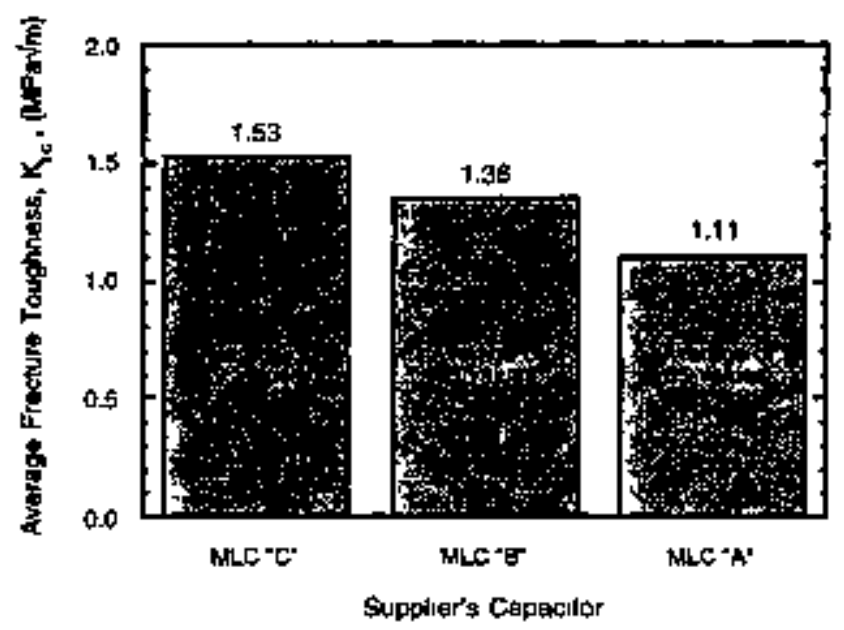

Figure 8. Fracture toughness comparison of the three MLCs.

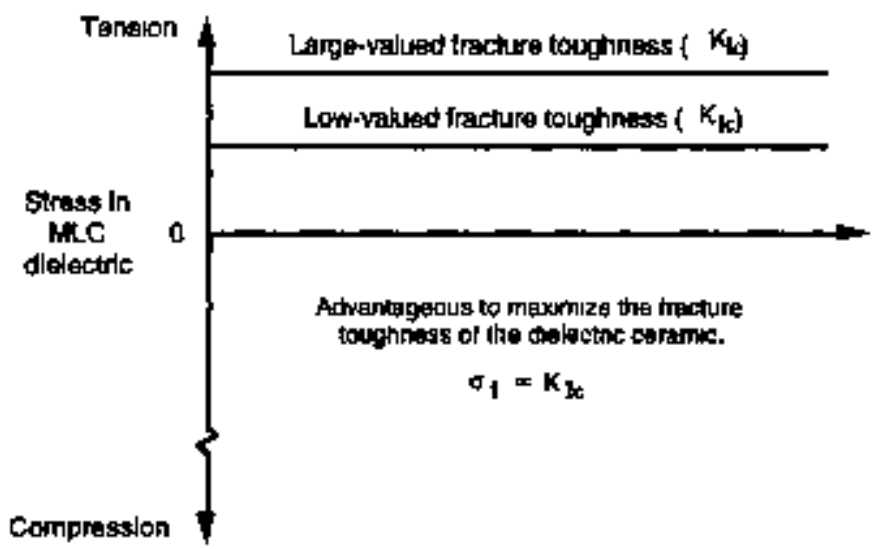


$\because+$

behavior of the tamination and electrode metats. residual stress, stress-iree temperature, adhesion strength of adjotining laminates in MLC cover layers, thickness of laminates comprising the cover kayer, glass fit effects, and themal shock susceptiblity can all affect MLC mechanical robustness $[1-2,10]$.

The authors belveve that appropriate design of a MLC, in which service- or manufacturing-induced tenslle stresses are minimized, will have more of an impact on Improved MLC mecharical robustness than any improvement in mechenical properties of $\mathrm{BaTlO}_{3}$ ceramics. Barium titanate cerarrics were never intended to be a structural ceraric, so a drastic improvement of their mechenlcal properties is untikely. The fracture toughnesses and strengths of structural ceramics, lke those for silicon ritride or partially-stabilzed zitconia, have doubled or even tripled over the years as their engineering has matured. However, is doubttul that $\mathrm{BeTtO}_{3}$ wil enjoy the same fracture toughness and strength development because there ts not an economlc driving force to fund that (unlike for silicon nitride and zirconta). Appropriate or improved design to limit service tensile stresses will likeiy have mone of an effect in the improvernent of MLC mectharical robustness than tinkering with $\mathrm{BaTlO}_{3}$ io make it twice us tough or strong. Engineering advances have increased the fracture toughness of structural ceramics up to 7-12 Mavatim doubling the fracture toughness of BaTiO, would increase it only to 2.5 .3 MParm. Additionally, structural ceramics can have flexure strengths larger than $1000 \mathrm{MPa}$, while the strengths of the strongest BaTO, cerarnics are an order of magnitude less [1]. Doubling the strength and fracture toughness of $\mathrm{BaTiO}_{3}$ corarrics would be helptul; however, designing MLCs so that Imposed tensile stresses are halved would result in the same mechanical robustness state, and would be much less of an engineering endeavor.

\section{CONCLUSIONS}

The present study consisted of the messurement of several mechanical properties of dielectric ceramics in MLCs. MLC mechanical reiliablity is a limiting factor to long-term electronic function, then it is clearty advantagaous to USe a MLC with maximum mecharical robustness. Maximum fracture toughness is described here as an indicator of the robustness.

The Young's modulus, hardness, and fracture toughness of the dledectrtc ceramics in three equivalent (X7R 0805 0.1 HF) MLCs were measuted in-situ. Ftorn a perspective of a stnuctural ceramic designer, the authors conclude that if the three MLC sets were to be subjected to an equal service stress state that the dielectric ceramic in the MLC-C would mechenically perform the best, followed in tum thy the dielectric ceramic to the MLC-A and then that in the MLC-B (all other thlngs being equal). This conclusion s based on the dielectric ceramic in MLC-C having the highest fracture toughness.

\section{ACKNOWLEDGMENTS}

Research sponsored by the $\downarrow$. S. Department of Energy, Assistant Secrefary for Energy Efficiency and Fenewable Energy, Office of Transportation, as part of the Advanced Automotive Materials Program under Contract DE+ACO5-960R22464, menaged by Lockheed Martin Energy Reseanch Corporation. The authors wish to thank H, - T. Lin, R. Ot, and A. Pasto for reviewing the manuscript and for their helpful comments. Lastly, the express appreciation for the support and assistance provided by Ford Motor Company's $\mathrm{G}$. Crosbie, Visteon Automotwe System's P. Crosby. KEMET's L. Mann, Murata's J. Canner, and ORNL's T. Kirkland, R. Bridge, and D. Stinton.

\section{REFERENCES}

1. Chip Type Monolithis Ceramio Capactor, Boncting SIrenglh Technical Data," Report TD.No.C05E, Murata Manufacturing Co., Lud., 1997.

2. A. A, Wereszczak, K Breder, L. Riester, T. P. Kirkland, and A. J. Brifge. Toward the Absessment of Mechanical Robustness of Ceramis Multilayer Capacitons (MLCs)," DOE/OANL-1999/202, in Intemal tevlew, October 1909.

3. S. W. Freimean and R. C. Pohanke, Roview of Mechanically Relared Falunes of Ceramic Capacttors and Capacitor Muterials," Joumad of the Amanican Ceramic Sociely, 72 2258-63 (1989).

4. W. C. Oliver and G. M. Pharr, "An Improved Techrique for Determining Hardness and Elastic Modulus Using Load and Displacement Sensing Indentation Experiments." Joumal of Materials Resuarch, 7 1664-83 (1992).

5. G. F. Ansts, P. Chantikul, B. R. Lawn, and D. B. Marshah, A Critlcal Evaluation of Indentation Techniquess for Measuring Fracture Toughness: I, Direct Crack Measurements," Joumal of the American Cerrmic Saclety, $64533-538$ (1981).

6. K Breder, A. A. Wereszczak, 2. Rlestar, and T. P. Kirkand "Determination of Strengh for Feliability Analysis of Mulwhyer Ceramic Capactilors" in press, Ceramis Enginesing and science Proceedings, Vol. 20. 1999.

7. c. A. Koripella, Mechenical Bahavior of Ceramic Capacitors," presented at the 41* Electronic Components and Technology Conterence (ECTC), May 13-15, 1991.

g. J. M. Blamey and T, V. Pary," "Sirength and Toughness of Barium Titanate Caramics," joumal of Materiais Scibnce, 28 $490 \%-4993$ (1993).

9. J. B. Quinn and G. D. Ouinn, "Indentation Buttleness of Cerambes: A Fresh Approach," Joumal of Materials Science, 32 4331-4346 (1997).

10. A. A. Wereszczak, K. Breder, M. K, Ferber, R. J. Bridge, L. Piester, and T, P. Kirkleand, "Falure Probability Preptiction of Dlelectric Ceramics in Mulitaver Capacitors," Mulblays Electronic Coramic Devices, Ceramic Transactions, Vol. 97, pp. 73•83, 1999. 